Título artículo / Títol article:
Neurobiology of social attachments

Autores / Autors

Coria Ávila, Genaro A.; Manzo, Jorge; García, Luis I.; Carrillo, Porfirio; Miquel SalgadoAraujo, Marta; Pfaus, James G.

Revista:

Neuroscience \& Biobehavioral Reviews

Versión / Versió:

Post-print

Cita bibliográfica / Cita

CORIA-AVILA, Genaro A., et al. Neurobiology bibliogràfica (ISO 690): of social attachments. Neuroscience \& Biobehavioral Reviews, 2014, vol. 43, p. 173182.

url Repositori UJI:

http://hdl.handle.net/10234/128287 
1 Review

\title{
Neurobiology of social attachments
}

\author{
Q1 Genaro A. Coria-Avila ${ }^{\mathrm{a}, \mathrm{d}, *}$, Jorge Manzo ${ }^{\mathrm{a}, \mathrm{d}}$, Luis I. Garcia ${ }^{\mathrm{a}, \mathrm{d}}$, Porfirio Carrillo ${ }^{\mathrm{d}}$, \\ Marta Miquel $^{\mathrm{b}}$, James G. Pfaus ${ }^{\mathrm{c}}$ \\ a Centro de Investigaciones Cerebrales, Universidad Veracruzana, Xalapa, VER, Mexico \\ b Universidad Jaume I, Castellon, Spain \\ ' Center for Studies in Behavioral Neurobiology, Concordia University, Montreal, QC, Canada \\ d Cuerpo Académico Neurociencias UV-CA-28, Universidad Veracruzana, Mexico
}

\section{A R T I C L E I N F O}

\section{Article history:}

Received 15 December 2013

Received in revised form 5 April 2014

Accepted 10 April 2014

\section{Keywords:}

Bonding

Attachment

Partner preference

Sex

Dopamine

Oxytocin

Learning

Love

\begin{abstract}
A B S T R A C T
Many types of social attachments can be observed in nature. We discuss the neurobiology of two types (1) intraspecific (with a partner) and (2) parental (with the offspring). Stimuli related to copulation facilitate the first, whereas pregnancy, parturition and lactation facilitate the second. Both types develop as consequence of cohabitation. These events seem to stimulate similar neural pathways that increase (1) social recognition, (2) motivation, reward; and (3) decrease fear/anxiety. Subregions of the amygdala and cortex facilitate social recognition and also disinhibition to decrease rejection responses. The interrelationship between MeA, BNST, LS may mediate the activation of NAcc via the mPOA to increase motivation and reward. Cortical areas such as the ACC discriminate between stimuli. The interaction between OT and D2-type receptors in NAcc shell facilitates intraspecific attachment, but D1-type appears to facilitate parental attachment. This difference may be important for maternal females to direct their attention, motivation and expression of attachment toward the appropriate target.
\end{abstract}

(c) 2014 Published by Elsevier Ltd.

\section{Contents}

1. Introduction

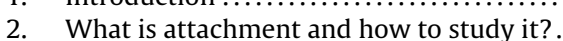

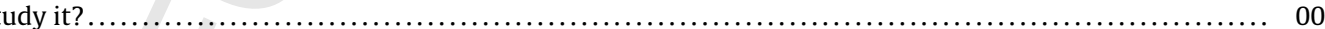

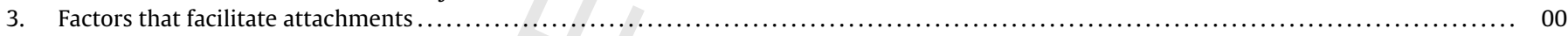

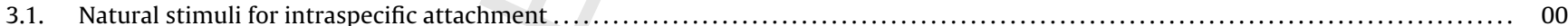

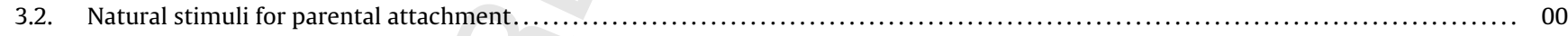

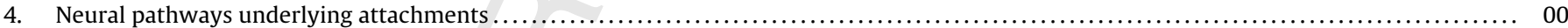

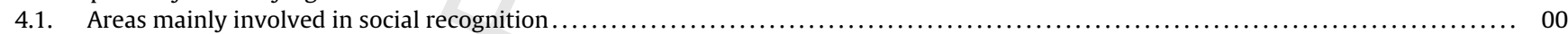

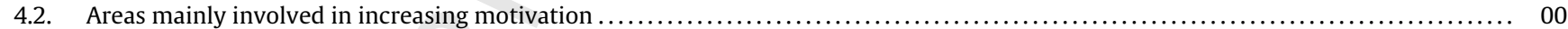

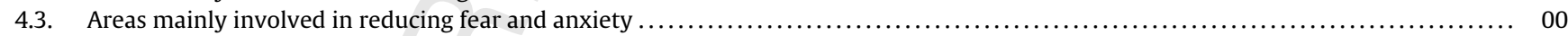

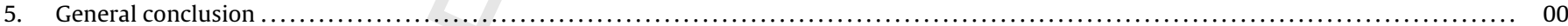

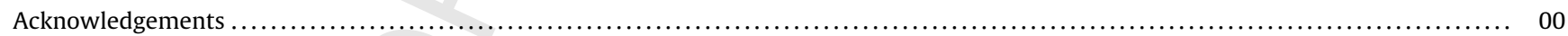

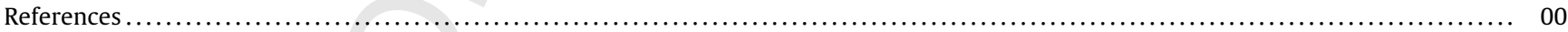

\section{Introduction}

Social attachments are necessary in many species because they facilitate reproduction, increase survival, provide a sense of security

\footnotetext{
* Corresponding author at: Centro de Investigaciones Cerebrales, Universidad Veracruzana, Avenida Luis Castelazo s/n Col. Industrial Ánimas, C. P. 91190 Xalapa, Veracruz, Mexico. Tel.: +52 228 8418900x13609; fax: +52 228 8418900x13611.

E-mail addresses: gcoria@uv.mx, coria75@yahoo.com (G.A. Coria-Avila).
}

and reduce feelings of stress and anxiety. Consequently, reproductive fitness and mental health depend to some extent on the capacity to form healthy attachments (Carter, 1998; Insel and Young, 2001). Many types of social attachments can be observed in nature. Some occur between opposite- and same-sex individuals, or between young and adult members of the same species; however, they can also occur between different species. In this review, we will explore two types only. One is referred to as "intraspecific attachment", and is typically observed between a male and a female around behaviors such as sexual partner preference and copulation 
that facilitate reproductive endpoints. The other is referred to as "parental attachment", and occurs between a parent and his/her young to facilitate survival of the offspring.

Intraspecific and parental attachments can occur either concomitantly or separately, but one is not required or sufficient for the other to occur. For example, an individual can be attached to his/her young and not to a partner, or vice versa. For these attachments to be displayed, animals must integrate external sensory signals with internal states and memories of previous experiences. Thus, to understand the neurobiology of attachment we must consider neural systems involved in social recognition, motivated behaviors, reward, memory and desinhibition. The aim of this review is to provide information on neural pathways underlying intraspecific and parental attachments. We begin by describing the objective measures of attachment in animal models. This is followed by a discussion of the evidence of the natural stimuli that facilitate attachments, and the putative neural systems that mediate the formation for each type.

\section{What is attachment and how to study it?}

Before describing the neural systems involved, it is important to understand the objective measures that indicate that one individual is attached to another. These measures are exclusively behavioral, and consequently, will vary from one species to another, although the end points served may be the same. In general, an attachment is a selective relationship with another individual (Carter, 1998; Insel, 2003), and in some species this selectivity is long-lasting. For example, monogamous voles show a long-lasting intraspecific attachment toward a partner they previously mated with or cohabited (usually for a 24 -h period). The attachment is expressed when animals have the choice of two partners and select one of them to spend more time, copulate and reproduce with. The attachment may last for life and attached individuals are rarely observed to mate with other partners even following permanent separation from the original one (Getz et al., 1993) which suggests rigorous selectivity (the attachment is either displayed toward the known partner or nobody). In contrast, other species like rats can show selective, but relatively brief copulatory preferences induced by Pavlovian learning (Kippin and Pfaus, 2001; Coria-Avila et al., 2005, 2006). This type of preference is considered brief because it may last for few ejaculatory series before they change partners (Kippin et al., 1998; Kippin and Pfaus, 2001). However, partner-related stimuli may well be preferred during long periods of life (Pfaus et al., 2001). Nevertheless, the behavioral differences between species with short- or long-lasting sexual partner, copulatory, or mate preferences can help to understand the neurobiology of attachments that occur naturally or that occur as a consequence of a relatively contrived conditioning process.

Parental attachment is assumed when females or males display behaviors that indicate the willingness to nurse and protect the young. In some species, parental attachment is rigorously selective and long-lasting, whereas in other species selectivity is not that rigorous. For example, some precocial species like sheep may display selective maternal behavior exclusively toward offspring they recognize as theirs during the very first hours postpartum (Kendrick et al., 1998). However, rats can foster pups that are not their own even ten days after parturition (Grota, 1973), indicating that the maternal behavior they provide is not strictly selective to their own, but rather toward any comparable newborn. Still, parental attachments expressed by rats require recognition of certain features of the target individual (i.e. neonatal looking). Furthermore, some ungulate (von Keyserlingk and Weary, 2007) and primate species (Davenport et al., 1961; Dienske and Van Vreeswijk, 1987) show long periods of maternal care, whereas lagomorphs display short periods (Schulte and Hoy, 1997). Regardless of the species, changes in time spent with the young or modifications in the frequency of maternal behaviors may be correlated with disruption or development of the parental attachment. In general, behaviors such as nursing, retrieving, licking or grooming directed toward the offspring, as well as voluntary time spent with them, and defense against intruders, can be described as parental behaviors in mammals that indicate attachment to the young. In the case of intraspecific attachment, selective copulation, time spent or voluntary contact with other individual can be the usual manifestation of attachment (Carter et al., 1995), however, other behaviors such as grooming, licking and mate-guarding among others, may also indicate the presence of an attachment.

\section{Factors that facilitate attachments}

\subsection{Natural stimuli for intraspecific attachment}

Many reproductive events can trigger a cascade of physiological responses that facilitate the formation of intraspecific attachments, and a good example occurs in female rats. During non-reproductive periods, the levels of gonadotrophin-releasing hormone ( $\mathrm{GnRH})$ in the hypothalamus activate the release of luteinizing hormone ( $\mathrm{LH})$ and follicle stimulating hormone (FSH) in the pituitary gland (Schally et al., 1971), causing a steady increase of estrogens (E) during the cycle. However, during the phase of proestrus, there is an increase in the pulse amplitude and frequency of GnRH, causing a rapid increase of LH and FSH (Hoeger et al., 1999), which in turn, produce a surge of $E$, testosterone $(\mathrm{T})$, and progesterone $(\mathrm{P})$. This particular hormonal state leads to estrus behavior and ovulation (Davidson et al., 1968; Lisk and Barfield, 1975). When copulation occurs, the female rat is prepared not only to accept the male and receive sexual stimulation (clitoral and vaginocervical), but also her brain is in a hormonal state that facilitates learning. The effect of hormones, and sexual stimulation are required for female rats to develop conditioned partner preferences triggered by sexual stimuli (Parada et al., 2010; Corona et al., 2011; Parada et al., 2011; Pfaus et al., 2012).

Hormones and copulation affect behavior similarly in females of species that display selective and long-lasting preferences. For instance, female prairie voles can develop a partner preference for a familiar male if are allowed to cohabit with him for a 24 -h period, but not during a period of $6 \mathrm{~h}$. However, females that cohabit and are allowed to copulate during the $6 \mathrm{~h}$ period, develop partner preference for the familiar male relative to an unfamiliar male. This demonstrates that intraspecific attachments (also referred to as pair bonds) can occur as a consequence of long periods of cohabitation, and that copulation facilitates them (Williams et al., 1992), acting as a catalyst. Some experiments with rats have shown that ejaculation is the main rewarding catalyst that induces the formation of conditioned partner preferences in males (Kippin et al. 2001). In female rats, sexual reward is mainly achieved by pacing the frequency of sexual contacts with the male, which facilitates a conditioned partner preference (Coria-Avila et al., 2005).

There are stimuli other than genitosensory stimuli that facilitate the formation of intraspecific attachments. For example in male prairie voles, long periods of swimming are believed to be stressful. If voles are placed to cohabit for less than $6 \mathrm{~h}$ with a partner, attachments will not develop. However, if they are forced to swim and then are placed to cohabit for a period of $6 \mathrm{~h}$, attachments are more likely to occur (DeVries et al., 1996; Carter, 1998). This is believed to be facilitated via the hormones that are released during the stress response (i.e. corticosteroids), since injections of corticosterone in males can also facilitate the formation of attachments that follow the injections (DeVries et al., 1996). The levels 
Table 1

Q4 Natural stimuli that facilitate attachments in different species.

\begin{tabular}{|c|c|c|c|c|}
\hline Stimuli & $\begin{array}{l}\text { Intraspecific } \\
\text { attachment }\end{array}$ & References & $\begin{array}{l}\text { Maternal } \\
\text { Attachment }\end{array}$ & References \\
\hline Cohabitation & & & & Jakubowski and Terkel (1985), \\
\hline With a partner & + & Williams et al. (1992) & $?$ & Rosenblatt (1967), Terkel and \\
\hline With pups & NA & & + & Rosenblatt (1972) \\
\hline Stress & & Carter (1998), DeVries et al. (1996) & & \\
\hline Forced swimming & ++ & & $?$ & \\
\hline Restrain & $?$ & & - & Champagne and Meaney (2006) \\
\hline Hormonal changes & & & & Gandelman et al. (1979) \\
\hline$E+P$ & ++ & Nelson (2000) & +++ & Misner and Houpt (1998) \\
\hline Corticosterone & ++ & DeVries et al. (1996) & $?$ & Steuer et al. (1987) \\
\hline Copulation & +++ & Williams et al. (1992) & & \\
\hline VCS & +++ & Coria-Avila et al. (2005) & +++ & Kendrick et al. (1991) \\
\hline Ejaculation & ++++ & Kippin and Pfaus (2001) & + & $\begin{array}{l}\text { Keverne et al. (1983) } \\
\text { vom Saal (1985) } \\
\text { Mennella and Moltz (1988) }\end{array}$ \\
\hline $\begin{array}{l}\text { Parturition } \\
\text { Lactation }\end{array}$ & NA & & ++++ & Rosenblatt et al. (1988) \\
\hline
\end{tabular}

The number of + indicates the relative facilitation of attachment. - indicates negative effects. NA, no applicable.

of plasma corticosterone may be increased in some males rats during copulation as well (Szechtman et al., 1974), suggesting another mechanism by which sex facilitates the development of attachments. Taken together, these examples demonstrate that intraspecific attachment can appear naturally among individuals that cohabit in a particular place, but events such as copulation, sexual reward, and stressful situations can facilitate its formation, acting as catalysts (Table 1 ).

\subsection{Natural stimuli for parental attachment}

In many species of mammals, maternal attachment normally appears following pregnancy, parturition and lactation. Pregnant females undergo drastic hormonal changes that prepare them to nourish and protect the young. In rats for example, concentrations of $P$ gradually start to rise since the very first day of pregnancy, peaking at day 15 , and drop considerably at the end of pregnancy. The levels of E remain relatively low, but increase dramatically at the end of pregnancy. The decrease of $P$ and increase of $E$ are the main mechanisms that induce rat parturition, although in primates, including humans, both hormones seem to increase during pregnancy and abruptly decrease during parturition (Rosenblatt et al., 1988; Nelson, 2000). Other hormones such as prolactin (PRL) increase during the first half of pregnancy and then decrease until the end of pregnancy, when they rise dramatically (Bridges, 1994). These hormonal changes lead to parturition and lactation, during which cervical and nipple stimulation, in turn, facilitate maternal attachment. However, hormones themselves can induce maternal behavior as observed in pseudo pregnant females that undergo all the hormonal changes without fetuses in the womb or parturition (Gandelman et al., 1979; Steuer et al., 1987). Some pseudo pregnant females (i.e. dogs) can even develop maternal attachment and direct it toward pup-like looking puppets (Misner and Houpt, 1998).

Stimuli that occur during parturition and lactation are the best natural stimuli that induce maternal attachment. Interestingly, in rats, exposure to pups during a week or more can induce maternal behavior even in non-pregnant females (Rosenblatt, 1967; Terkel and Rosenblatt, 1972), and also in males (Jakubowski and Terkel, 1985). Sensitized rats can retrieve and lick the pups, and they can also adopt a nursing posture and build a nest. This indicates that parental attachment may appear as a consequence of daily exposure to pups as well, but hormones, parturition and lactation are stimuli that function as catalysts to facilitate its formation. Another example is observed in nulliparous ewes. Natural vaginocervical stimulation (VCS) caused by the pass of the lamb through the pelvic canal, or artificial VCS (provided by hand) in non-pregnant ewes, facilitate maternal attachment if they were previously primed with P and E (Keverne et al., 1983; Kendrick et al., 1991). Likewise, castrated male rats (not gonadally intact) respond to $\mathrm{E}+\mathrm{P}$ which also facilitate parental behavior (Rosenblatt et al., 1996).

Parental behavior can also be facilitated by the sexual reward that accompanies reproductive behaviors in intact males. For example, in male rats (Mennella and Moltz, 1988; Pfaus et al., 2001) and mice (vom Saal, 1985), ejaculation blocks infanticide and facilitates parental behavior. More than $90 \%$ of male mice will normally commit infanticide if exposed to pups between 1 and 4 days after mating with a female. This indicates that during those few days, males do not develop parental attachment toward pups. However, between 80 and $90 \%$ of those males will behave parental and will not kill the pups if are exposed to them 12-50 days after ejaculating. Given that the average period of gestation in mice is 21 days, it might indicate that there is a timed association of ejaculation and being a father. Those males will not behave fully parental, but the absence of infanticide reflects a degree of tolerance and perhaps attachment to the pups. This suggests that the contingency between ejaculation and exposure to pups is important for the induction of pup tolerance or parental attachment, although the actual mechanisms are not known. Taken together, the data on intraspecific and parental attachments indicate that they can be formed during cohabitation with partners or pups, respectively. In addition, stimuli associated with sexual reward or reproduction, as well as some hormonal changes, facilitate the formation both types of attachment (Table 1 ).

\section{Neural pathways underlying attachments}

Stimuli such as copulation, mild stress and cohabitation facilitate the development of intraspecific attachments between males and females. Accordingly, those natural stimuli must activate the same neural pathways, perhaps at different velocity (i.e. copulation vs. cohabitation). Likewise, parturition, VCS, lactation, nipple stimulation, or the mere cohabitation with pups, may facilitate the development of parental attachment. Thus, given that these two types of attachments may occur concurrently or separate, at least two neural circuitries must exist, perhaps sharing some common neural areas. Such neurocircuitries should be involved in social recognition, inhibition of fear, reward and motivation, which collectively mediate the formation and expression of attachments. 


\subsection{Areas mainly involved in social recognition}

In order to display a social attachment, social recognition is expected to occur first. Studies in animals have helped to identify areas in the brain activated during social encounters and during recognition. For example, mice with depletion of oxytocin (OT) show impairments in olfactory social recognition, but not in normal olfaction (Bielsky and Young, 2004). That is, they can easily remember odors of food they have been exposed to, but fail to remember individuals they just cohabited with, and consequently display longer olfactory investigations. A study using c-Fos immunoreactivity (Fos-IR) as a marker of neuronal activation showed that wild-type and OT knock-out mice expressed similar Fos-IR after a social encounter in the olfactory bulbs, piriform cortex (Pir Ctx), cortical amygdala (CoA), and the lateral septum (LS). However, OT knock-out mice exhibited less Fos-IR in the medial amygdala (MeA), bed nucleus of the stria terminalis (BNST) and medial preoptic area (mPOA), suggesting that MeA, BNST and mPOA are brain areas where olfactory social recognition occurs. Further studies showed that OT in the MeA is both necessary and sufficient for social recognition (Ferguson et al., 2001; Bielsky and Young, 2004), since OT alone restored the capacity to recognize individuals. It is important to mention that fully functional OTR binding in the MeA is required for normal social interest in male rats (Dumais et al., 2013), which in fact, can be activated not only by OT, but by arginine vasopressin (AVP) as well (Hawtin et al., 2000).

During orgasm in humans, and VCS, parturition and social encounters in animals the concentration of OT increases in the cerebrospinal fluid (CSF), and in hypothalamic and mesolimbic areas (Fuchs et al., 1982; Carmichael et al., 1987; Gimpl and Fahrenholz, 2001; Insel et al., 2001; Bielsky and Young, 2004). Accordingly, those natural stimuli may facilitate attachments, in part, because they facilitate social recognition via OT. However, social recognition alone is insufficient. In fact, pathways of reward and motivation must be activated concurrently, and those associated with fear must be inactivated to facilitate the development and expression of attachments (Fig. 1). For example, when female rats have sex sensory information from the clitoris and vagina is transmitted via the pudendal and pelvic nerves, respectively (Ueyama et al., 1987; Yucel and Baskin, 2004), and input from the uterus is transmitted via the hypogastric nerves (Berkley et al., 1988). The sensory afferents of these nerves terminate bilaterally in the dorsal horns of the lumbosacral spinal cord which show activation during VCS (Lee and Erskine, 1996). Furthermore, an ascending pathway from the lumbosacral area arrives to the nucleus of the tractus solitarius (NTS) and midbrain periaqueductal gray matter (PAG). These two nuclei have been suggested as good candidates to mediate the OT and AVP release during the formation of attachments (Young et al., 2005). The NTS receives direct projections from the lumbosacral neurons (Menetrey and Basbaum, 1987), and electrophysiological studies have demonstrated that most of the NTS neurons respond with activity following VCS (Berkley et al., 1988, 1993). The NTS projects to the PVN in the hypothalamus, and directly stimulates the parvocelullar neurons that produce OT and AVP. However, the lumbosacral neurons also project directly to the PAG (Mouton et al., 1997) and PAG neurons also project and stimulate the PVN (Marson and Murphy, 2006). The PVN can release OT into the MeA to facilitate olfactory recognition, which in turn can facilitate motivated behaviors through its dense interconnections with the MPOA and BNST (Been and Petrulis, 2011). A normal social encounter without copulation can also activate the MeA and mPOA (Dhungel et al., 2011), although presumably more slowly than after sex. MeA and $\mathrm{MPOA}$ regulate the recognition and attraction toward sexually available partners, but also regulate sexual performance, integration of reward and neuroendocrine cascades that follow sex. In the case of social encounters the MeA is more responsive with non-volatile odors (normally present in bedding soiled with the excreta of estrous females, or partners), whereas mPOA (and CoA) respond more with volatile odors (from physically inaccessible partners) (Dhungel et al., 2011; DiBenedictis et al., 2012) (Fig. 1).

As we mentioned above, monogamous prairie voles can easily develop interspecific and parental attachments. Female voles express naturally more binding of OT receptors in the amygdala (specially CoA and lateral parts), as compared to polygamous voles. In addition, they express more OT receptors in the ventromedial nucleus of the hypothalamus (VMN) and mesolimbic areas such as the nucleus accumbens (NAcc), prefrontal cortex (PFC), BNST, and anteroventral thalamic nucleus, relative to polygamous females (Insel and Shapiro, 1992). Of all these areas, only NAcc and PFC appear to mediate attachments, since infusions of OT antagonists into these two areas prevent the formation of attachment induced by copulation (Young et al., 2001). This may indicate that OT released by sex not only facilitates social recognition by acting on the amygdala, but also mediates motivation by acting on NAcc neurons along with dopaminergic (DA) inputs. Interestingly, cohabitation alone also increases the expression of tyrosine hidroxilase immunoreactivity (precursor of DA) in the MeA (Cavanaugh and Lonstein, 2010), which suggest that OT and DA function concurrently in amygdala and NAcc to facilitate recognition and motivation.

As mentioned above, AVP also mediates olfactory social recognition and is produced and centrally released by the PVN into the hypothalamus (De Vries and Buijs, 1983). Monogamous voles have a higher density of AVP receptors in the ventral pallidum (VP) as compared to polygamous voles (Lim and Young, 2004). The VP also receives projections from the MeA and NAcc (Heimer et al. 1991; Klitenick et al., 1992). Thus, it is well situated to mediate important information from olfactory recognition and motivation. In fact, the infusion of an AVP receptor antagonists into the VP, prevents mating-induced intraspecific attachments (Young and Wang, 2004). The natural expression of OT and AVP in those neurocircuitries may explain how some species are more naturally sensitive than others to form attachments (i.e. monogamous vs. polygamous voles). Nevertheless, repeated exposure to social recognition paired with some types of reward can sensitize similar neural areas as observed in polygamous rats that express conditioned partner preferences after a period of learning (Coria-Avila et al., 2005, 2006; Coria-Avila, 2007; Paredes-Ramos et al., 2011; Cibrian-Llanderal et al., 2012; Coria-Avila, 2012; Paredes-Ramos et al., 2012).

In one human study, functional magnetic resonance imaging (fMRI) was used to measure brain activity in female volunteers who viewed pictures of their lovers and children, and it was compared with activity evoked by pictures of other infants, or acquaintances. Exposure to the lover's picture induced activation in areas associated with memory such as the dentate gyrus in the hippocampus (Bartels and Zeki, 2004) which expresses AVP receptors in the human brain (Sofroniew et al., 1981). Accordingly, AVP might mediate the formation and expression of attachments in humans as well, even if social recognition occurs via visual stimuli. With regard to visual recognition, the study by Bartels and Zeki also showed activation in the ventral region of the anterior cingulate cortex (ACC) (Bartels and Zeki, 2004). The activation of the ACC is usually related to autonomic functions like heart rate, and blood pressure control, but also cognitive functions like reward anticipation, and discrimination of stimuli (Parkinson et al., 2000). It was argued that during observation of pictures, the ACC is activated to discriminate between faces, or other general stimuli that may help to direct the selective behavior toward an individual. Some other areas that were activated seemed to be part of a common neural system for both types of attachment and these included the VTA and the medial insula (Bartels and Zeki, 2004). The VTA is the site of origin of mesolimbic DA neurons that project diffusely to 


\section{Natural stimuli that mediate attachments}

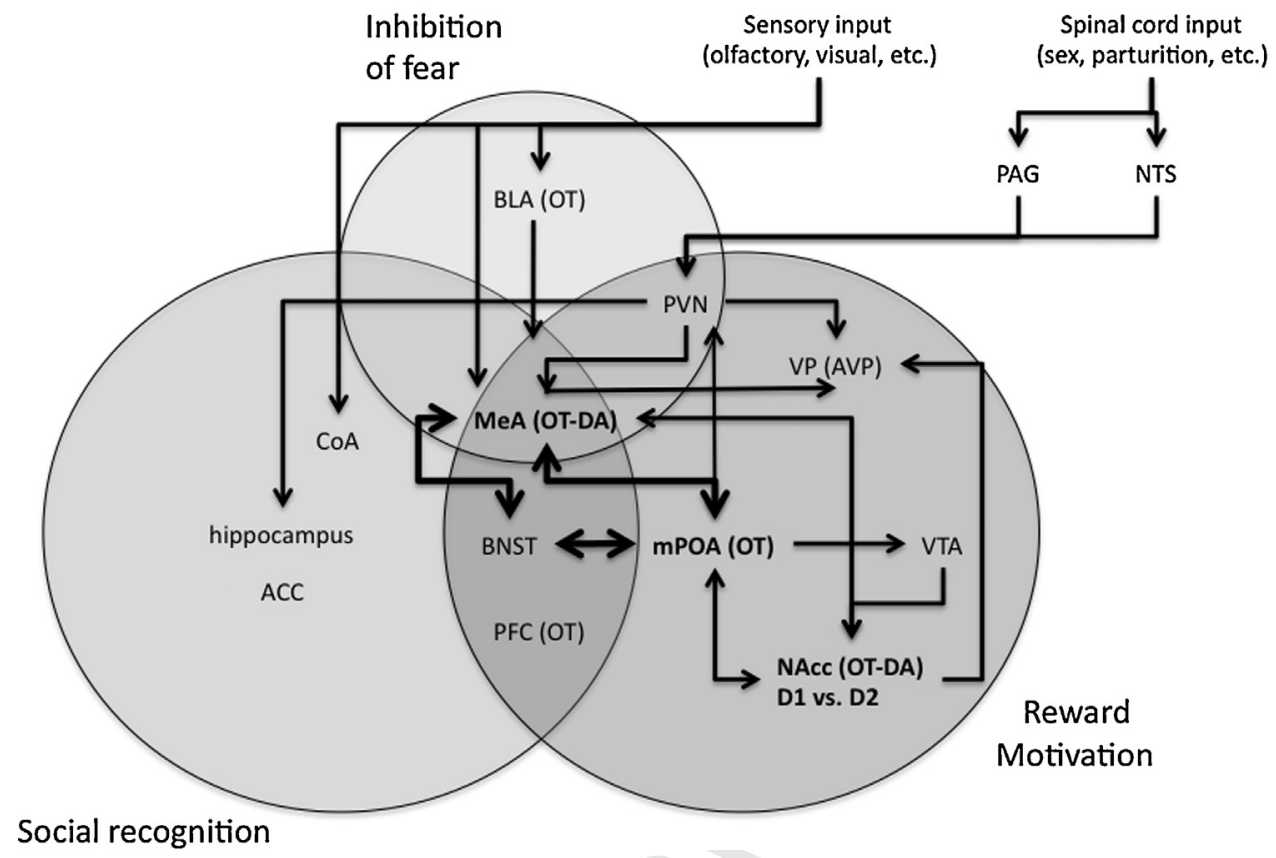

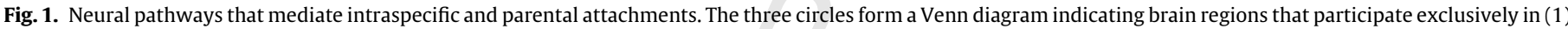

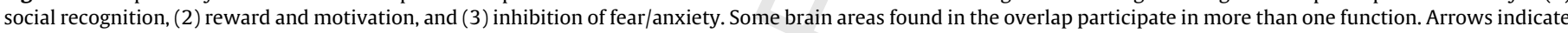

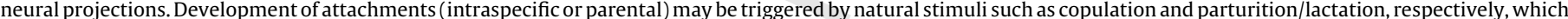

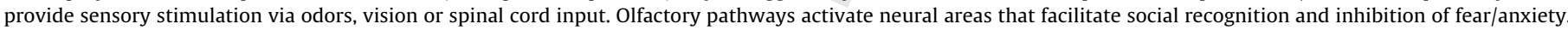

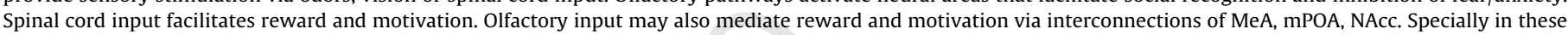

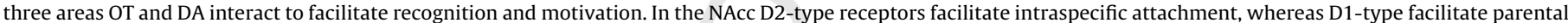

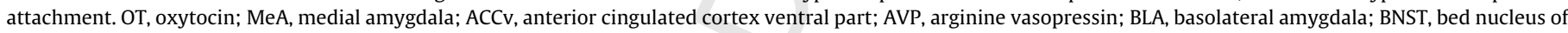

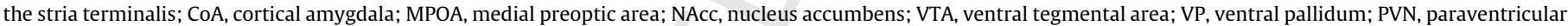
nucleus; PAG, periaqueductal gray matter; PFC, prefrontal cortex; NTS, nucleus tractus solitarius. See general conclusion for explanation of the pathway.

limbic structures, such as the NAcc, amygdala, and septum, as well as cortical regions like the ACC, which mediate motivation and attention, and the medial insula, a cortical area related to the visceral sensations induced by visual stimuli.

\subsection{Areas mainly involved in increasing motivation}

Motivation to express a social attachment commonly starts after social recognition or during prediction of reward. Studies in male rats have demonstrated that estrus odors (Kelliher et al., 1999) or conditioned odors that predict copulation with the preferred partner (Kippin et al., 2003) induce Fos-IR within the NAcc. In fact, many areas involved in recognition project to the NAcc facilitating motivation toward well identified individuals. However, the NAcc not only mediates motivation and attention, but is also a key area in the consolidation of attachments. For instance, neurons of the NAcc in monogamous voles express more OT receptors than in the polygamous voles (Insel and Shapiro, 1992), but is the interaction of OT and DA within the NAcc what mediates the formation of intraspecific attachments in monogamous voles. Namely, an OT antagonist disrupts attachments facilitated by DA agonists, and vice versa (Liu and Wang, 2003). Infusions of DA antagonists (i.e. haloperidol) either into the NAcc or systemically injected, also disrupt the partner preference formation after copulation, whereas low doses of DA agonists (i.e. apomorphine) facilitate attachments (Gingrich et al., 2000; Aragona et al., 2003). Interestingly, copulation induces a release of DA in the NAcc not only in monogamous voles, but also in promiscuous species like rats (Pfaus et al., 1990, 1995). It has been proposed that although DA is sufficient to induce attachments in voles, it should not be considered "the neurotransmitter" for attachments in other species (Insel, 2003; Young and Wang, 2004;
Aragona et al., 2006), although rats indeed form strong partner preferences after a process of conditioning. Consequently, it is likely that having a working DA system is necessary, but not sufficient to induce long-lasting and rigorously selective social attachments, like those observed in monogamous species.

In other experiments it was found that DA either facilitates or inhibits the formation of attachments, depending on the DA-type receptor that it binds to. In voles, NAcc DA is critical for attachments, especially via the D2-type receptors. In one study, the blockade of NAcc DA with the D2-like receptor antagonist eticlopride prevented the formation of selective and long-lasting intraspecific attachment after mating, or after $24 \mathrm{~h}$ of cohabitation (Gingrich et al., 2000). In the same study, females infused with the D2-type receptor agonist quinpirole, developed attachment toward a familiar male even during short periods of cohabitation, or without mating. Almost one decade ago it was shown that, D1- and D2-type receptors have opposite roles (Aragona et al., 2006). For example, within the rostral shell of male voles, activation of D1-type receptors prevents the formation of attachment toward a familiar partner, whereas activation of D2-type receptors facilitates it. In fact, males that have developed a selective and long-lasting preference show significant upregulation in D1-like receptors within the rostral shell. It has been argued that D1-like receptors in those monogamous males may function to prevent the formation of attachments more than once (Aragona et al., 2006). After all, a monogamous individual cannot be attached to more than one partner at the same time.

Aragona and colleagues have suggested the following process during the formation of attachments: In monogamous species, copulation-induced DA activates D2-like receptors, which in turn, induce attachment. Further DA release may activate the remaining D1-like receptors, which consequently will prevent the formation 
of attachments with another individual. In the polygamous species however, D1-like receptors are more abundant relative to the amount of D1 receptors in monogamous species (Aragona et al., 2006). D1-like receptors are activated first by the DA released during copulation, which prevent an immediate attachment. Based on those findings, we speculate that repeated contingency between a partner and reward (during conditioning of partner preference) might induce increased activity of the D2-like receptor, which eventually results in a form of attachment (learned preference) induced by Pavlovian conditioning. In a polygamous species, the development of immediate intraspecific attachment in an individual may represent a disadvantage to its reproductive fitness relative to the other members of the species. As a result, in polygamous species like rats, the formation of attachments takes longer time and repeated associations.

Very recently, we demonstrated that rats treated with the D2type agonist quinpirole (QNP) develop attachment toward "any" partner they are exposed to under the effects of QNP. In our first experiment, sexually-naïve male rats were injected with $1.25 \mathrm{mg} / \mathrm{kg}$ of QNP I.P. and then were immediately placed to cohabit for $24 \mathrm{~h}$ with another male. This process was repeated every four days, for a total of 3 trials. Four days after the last conditioning trial males were tested for partner preference between two potential partners. One was a sexually receptive female and the other was the familiar male they cohabited with. Our results indicated that QNP-treated male rats (but not saline-treated) displayed a very robust social-sexual preference for the male, and ignored the receptive female, which demonstrates the powerful effect of the D2-type receptors activity on the development of intraspecific attachments (Cibrian-Llanderal et al., 2012).

With regard to parental attachment, dopamine is released in the NAcc of female rats following exposure to pups (Hansen et al., 1993), and during licking and grooming of the pups (Champagne et al., 2004). DA activity is directly correlated with maternal performance. For example, in rats that perform high frequency of licking behavior, DA levels are higher relative to low-licking dams, and subcutaneous injections of DA uptake inhibitors (which enhance DA activity in the synapses) increased maternal activity in those naturally low-licking/grooming rats (Champagne et al., 2004). DA antagonists also affect maternal behavior. In one study, maternal behavior of lactating rats was assessed following infusions with flupenthixol into the NAcc, or into the CPu (an area also rich in DA receptors). It was found that only those females infused into the NAcc displayed impaired pup retrieval and licking (Keer and Stern, 1999). Furthermore, abnormally high levels of DA also affect maternal behavior. For example, chronic cocaine infusions increase the latencies to build a nest, and to crouch over pups, and affect the duration of crouching (Johns et al., 1994). This demonstrates that abnormal low or high levels of DA in the NAcc, affect parental attachment.

One decade ago, it was suggested that DA may be a neuromodulator that signals reward and satiety for maternal behavior (Insel, 2003). The reward and satiety suggested by Insel (2003) may be mediated by the differential role of $\mathrm{D} 2$ and $\mathrm{D} 1$ receptors, as observed with the facilitation and prevention of intraspecific attachment in voles. Numan and colleagues provided a good example in a study on maternal behavior. They showed that in lactating rats, injections of a D1-like antagonist (SCH23390) in the NAcc, disrupted pup retrieval, whereas a D2-like antagonist (eticlopride) had no effects (Numan et al., 2005). If we consider pup retrieval alone as an indication of maternal attachment, then it is possible to speculate that intraspecific and parental attachments may be formed via activation or deactivation of the same DA receptors, but in an opposite manner. Thus, maternal females under the facilitatory effect of D1-type receptors would have an impaired capacity to form intraspecific attachment (which are blocked by D1-type receptors).
Such opposite effect would facilitate attention toward the young and not toward a partner, which guarantees their survival.

Indeed, lactating female rats with access to pups, express FosIR in the NAcc (Lonstein et al., 1998), but also the mPOA, the BLA and CeA regions of the amygdala (Fleming and Walsh, 1994). Thus, the mPOA and the NAcc may be part of the effector's system in the expression of both maternal and intraspecific attachments (presumably depending on the DA receptor activated), and not only for recognition of odors (Walsh et al., 1996). In rats, lesions in the MPOA disrupt maternal behavior, but also decrease the Fos-IR in the NAcc shell usually expressed following exposure to pups (Stack et al., 2002), probably because of the interconnections between mPOA, NAcc and VTA. Lesions in the NAcc alone are also associated with disruption of pup retrieval, and less bar pressing to get access to pups (Lee et al., 2000) and lesions in the VTA disrupt the frequency of approaches and interaction with pups (Gaffori and Le Moal, 1979; Lee et al., 1999). Interestingly, OT in the mPOA and DA in the NAcc interact to mediate maternal attachment. Meaney and colleagues showed that female rats that display high levels of maternal behavior (i.e. licking/grooming) show increased OT expression in the mPOA and PVN, and these two areas project more OT-positive cells to the VTA. OT into the VTA increased the DA signal in the NAcc, which mediates motivation to develop and express attachments (Shahrokh et al., 2010).

\subsection{Areas mainly involved in reducing fear and anxiety}

In addition to social recognition and motivation, individuals must reduce their fear and anxiety to facilitate social encounters. Usually, mild levels of fear and anxiety will keep animals alive and in defensive mode. So, to be close to another, that tendency has to be reduced in addition to strengthening the bonding that brings animals into close proximity. This could be accomplished in one or all of three ways: first to augment the bonding; second to decrease the fear, and third a mix of the two. This dichotomy in excitatory-inhibitory mechanisms has been previously suggested for the control of other motivated behaviors, such as sexual desire (Pfaus, 2009).

For instance, lesions at any level along the vomeronasal inputs to the MPOA accelerate the onset of maternal behavior even in nulliparous female rats (Fleming and Rosenblatt, 1974a,b,c). Olfactory stimuli activate neurons that directly project to the amygdala. Consequently, an integrative model has suggested that the mPOA coordinates maternal behavior when it gets released from the inhibitory effects of the amygdala (Fleming and Korsmit, 1996). In some species with rigorous selectivity (i.e. sheep) this would result in parental attachment only if there is specific social recognition of the young, but in other species (i.e. rats) specific social recognition may not be required, but rather recognition of a target individual that looks like the offspring or bears neotenic features.

The inhibitory effect of the amygdala may depend on the subarea and also on the species studied. For example, ewes injected in the CoA or MeA with lidocaine (a local anesthetic) during the very first 8 hours postpartum, have an impaired ability to recognize their lambs, but not with injections in the BLA (Keller et al., 2004). This finding is in accordance to the role of MeA in olfactory recognition, but it also indicates that MeA must be activated (by OT, DA) and not inhibited (as occurs with lidocaine) for social recognition to occur. Fear and anxiety toward the young may decrease after OT and DA have worked on MeA. On the other hand, BLA may be also a subarea responsible of decreasing anxiety to facilitate maternal performance. There is evidence in other species indicating that OT within the BLA directly affects maternal behaviors. In monogamous prairie voles, for example, nulliparous females display maternal behavior and pup care at any time (Insel and Shapiro, 1992). However, females of polygamous species of voles only display maternal 
behavior after parturition. The sudden ability to display maternal attachment is associated with a significant increase in OT binding in BLA (Insel and Shapiro, 1992). Such maternal performance is similar to what occurs normally in monogamous voles of both sexes when they are exposed to pups. The BLA has been also associated with fear responses (Inoue et al., 2013), and some experimental data indicate that OT within the BLA may reduce fear (Lahoud and Maroun, 2013) which in turn would facilitate approach behavior to the pups, driven by the integrator areas.

Some studies have explored brain activity in maternal rats combining Fos-IR and autoradiography with 14C-2-deoxyglucose (2-DG), which can be used as a marker of activity at axonal terminals. Combining Fos-IR and 2-DG, researchers can observe the effects of a stimulus on the input and output of a neuron. For instance, following parturition or sensitization to pups, maternal female rats express more Fos-IR (more input) but less 2-DG (less output) in the vomeronasal tract and MeA (Komisaruk et al., 2000). Perhaps the MeA is receiving more input from the olfactory pathways, which decreases its output toward MPOA (and other regions). This whole process is probably related to better social recognition and less fear. Furthermore, in other brain areas such as mPOA, BNST, LHab, PAG, thalamus, LS and VTA, Fos-IR (input) and 2-DG (output) are positively correlated (Komisaruk et al., 2000), probably facilitating recognition, reward and motivation.

In women, exposure to the picture of their own child also induced deactivation of the amygdala (less fMRI activity), as compared with the basal levels of activation of the volunteers before watching the picture (Bartels and Zeki, 2004). Such deactivation is partially consistent with the association of amygdala with negative emotions such as aggression (Eichelman, 1983), negative social judgment (Adolphs et al., 1998), and with its inhibitory role on the mPOA. Perhaps, it also may indicate reduction or inhibition of fear and anxiety. Furthermore, simultaneous deactivations occurred in the middle prefrontal cortex, inferior parietal cortex, and middle temporal cortex (Bartels and Zeki, 2004). All three cortices play a key role in attention and memory, but their activation has also been shown to be involved in negative emotions such as depression or sadness (Beauregard et al., 1998). The parietotemporal junction, and medial prefrontal cortex (MPFC) were also deactivated in women that observed the picture of their own child (Bartels and Zeki, 2004). Those areas have been involved in the ability to determine others people emotions and intentions. Some homologies regarding these brain areas may be found in ewes. To be exact, in one experiment, deactivation of the MPFC with local anesthetic injections (tetracaine) did not prevent the formation of an olfactory memory toward lambs, but this procedure successfully inhibited aggressive behavior toward unfamiliar lambs (Broad et al., 2002). Thus, the amygdala, and some parts of the prefrontal, parietal and temporal cortices mediate prevention of negative social behavior toward the offspring. This suggests that odors of the offspring become less aversive, and under the appropriate hormonal state this facilitates maternal behavior, although not necessarily selective maternal behavior.

In women, maternal attachment also induces activation of the ACC (Bartels and Zeki, 2004). In ewes, the ACC expresses Fos-IR during recognition of the lamb (Kendrick et al., 1997). In addition, female rats that receive lesions within the ACC show disruption of maternal behavior (Devinsky et al., 1995). As discussed in the section of intraspecific attachments, the ACC is important for recognition of stimuli that might look alike; in other words, normal activation of the ACC may function to identify clearly the target individual when attachments must be expressed. This recognition seems to occur via the incentive value of the stimuli (Parkinson et al., 2000). In addition, women exposed to the picture of their own children, expressed activation on the lateral fusiform gyrus, important for face and color recognition (Bartels and Zeki, 2004).
OT and its receptors (OTR) may also reduce fear and anxiety during the display of parental attachments. Experiments with rats have shown that following parturition, OTR increase more than $80 \%$ in areas such as the BNST (Insel, 1992), and natural variations in maternal behavior are correlated with variations in the number of receptors in this area, but also in the $\mathrm{mPOA}$, LS, and CeA. For example, rats with high levels of grooming and licking toward the pups (indicative of better maternal behavior) express more OT receptors in the mPOA, LS, BNST, and CeA (Champagne et al., 2001). The amount of OTR expressed in these areas may be indicative of greater capacity for parental attachment and less fear to interact with pups. Indeed, studies have shown that antisense DNA against OTR results in impaired social recognition (Choleris et al., 2007). As expected, OT-knockout mice display impaired social recognition, but surprisingly they express complete maternal behavior. Those mice have a functional OTR although the peptide that is to act on them is nonfunctional. Thus, it has been argued that mice and perhaps other species may not require OT to display maternal behavior (Insel et al., 2001), although it is very likely that other neurotransmitters such as AVP facilitate maternal behavior by activating the fully functional OTR in OT-knockout mice (Hawtin et al., 2000). This can also indicate that OT mediates social recognition, but not maternal attachment. Consequently, females without OT may be maternal but not strictly selective. It is possible that OT and AVP receptors distribution in the brain and maternal selectivity may depend on the intrinsic evolutionary needs of a species (i.e. precocial vs. altricial), but may also depend on the needs of a gender. For instance, some forebrain regions in female rats (e.g. NAcc, CP, LS, BNST, MeA and VMH) express normally less OTR binding density as compared to males (Dumais et al., 2013). Such differences have been correlated with the inherent social interest that each sex expresses toward unfamiliar conspecifics.

Fear and anxiety can also be reduced by the same natural stimuli that facilitate attachments. In different species, endogenous opioids increase after copulation (Agmo and Berenfeld, 1990; Band and Hull, 1990; Rodriguez-Manzo and Fernandez-Guasti, 1995; AcostaMartinez and Etgen, 2002; Coolen et al., 2004; Phillips-Farfan and Fernandez-Guasti, 2009) and during parturition (Wardlaw and Frantz, 1983). Indeed, opioids regulate OT release (Neumann et al., 1992), but they also facilitate DA release from the VTA into the prefrontal cortex and NAcc (Kalivas and Abhold, 1987). Evidence in humans also indicate that endogenous opioids play a role in emotion regulation, and in the reduction of fear recognition sensitivity (Ipser et al., 2013). Accordingly, enhancement of endogenous opioids during sex or parturition may facilitate the development of intraspecific and parental attachments not only because they facilitate rewarding associations, but also because individuals are less sensitive to recognize a partner or a pup as a source of fear or anxiety.

\section{General conclusion}

Many examples were given here to support the idea that there is not a single neural system that controls attachments. Rather, a combination of areas involved in social recognition, motivation, reward, memory, and fear/anxiety mediate the formation, expression and maintenance of attachments. In this regard, a common neural system appears to underlie both intraspecific and parental attachments. These may occur as consequence of various physiological events. If it is directed toward a partner (intraspecific) it may be facilitated by copulation or sexual reward in general; however, if it is directed toward the young (parental) it may be facilitated by events such as pregnancy, parturition and lactation. Both types may also develop as consequence of cohabitation. These events seem to stimulate similar neural pathways. Subregions of 
the amygdala and cortex facilitate recognition and disinhibition to enhance motivation and decrease rejection responses. The interrelationship between MeA, BNST, LS may mediate the activation of NAcc via the mPOA. The incentive aspects of the stimuli in the NAcc are also modulated by cortical areas such as the ACC, which participates in the discrimination between stimuli. Consequently, ACC may orchestrate part of the behavioral output, directing the appropriate responses toward a pup or a partner. The discrimination must be processed simultaneously with other stimuli that might have an incentive value (i.e., memories of sexual reward, maternal reward, etc.), occurring in the hippocampus. The interaction between OT and D2-type receptors in NAcc shell facilitates intraspecific attachment, but D1-type appears to facilitate parental attachment. This difference may be important for maternal females to direct their attention, motivation and expression of attachment toward the appropriate target. Over all, we can conclude that intraspecific and parental attachments seem to share common neural systems. This is based on the fact that natural stimuli that facilitate those types of attachments increase or decrease activity within similar areas. However, the presence of Fos-IR may also represent the activation of inhibiting inputs, and the amygdala is a good example. The mechanism that differentiates a bonded animal from a non-bonded might depend on the activity of different types of receptors within the same areas. Therefore, it is not surprising that many brain areas show similar activation during the two types of attachment. Overall, the neural areas required to induce the formation of attachment must be those that facilitate social recognition and reproduction but also those that reduce feelings of stress and anxiety.

\section{${ }_{741}$ Acknowledgements}

Cuerpo Académico UV-CA-28 Neurociencias. Grant SEPCONACYT (167773) to GACA.

\section{References}

Acosta-Martinez, M., Etgen, A.M., 2002. Activation of mu-opioid receptors inhibits lordosis behavior in estrogen and progesterone-primed female rats. Horm. Behav. 41, 88-100.

Adolphs, R., Tranel, D., Damasio, A.R., 1998. The human amygdala in social judgment. Nature 393, 470-474.

Agmo, A., Berenfeld, R., 1990. Reinforcing properties of ejaculation in the male rat: role of opioids and dopamine. Behav. Neurosci. 104, 177-182.

Aragona, B.J., Liu, Y., Curtis, J.T., Stephan, F.K., Wang, Z., 2003. A critical role for nucleus accumbens dopamine in partner-preference formation in male prairie voles. J. Neurosci. 23, 3483-3490.

Aragona, B.J., Liu, Y., Yu, Y.J., Curtis, J.T., Detwiler, J.M., Insel, T.R., Wang, Z., 2006 Nucleus accumbens dopamine differentially mediates the formation and maintenance of monogamous pair bonds. Nat. Neurosci. 9, 133-139.

Band, L.C., Hull, E.M., 1990. Morphine and dynorphin(1-13) microinjected into the medial preoptic area and nucleus accumbens: effects on sexual behavior in male rats. Brain Res. 524, 77-84

Bartels, A., Zeki, S., 2004. The neural correlates of maternal and romantic love. Neuroimage 21,1155-1166.

Beauregard, M., Leroux, J.M., Bergman, S., Arzoumanian, Y., Beaudoin, G., Bourgouin, P., Stip, E., 1998. The functional neuroanatomy of major depression: an fMRI study using an emotional activation paradigm. Neuroreport 9, 3253-3258.

Been, L.E., Petrulis, A., 2011. Chemosensory and hormone information are relayed directly between the medial amygdala, posterior bed nucleus of the stria terminalis, and medial preoptic area in male Syrian hamsters. Horm. Behav. 59, 536-548.

Berkley, K.J., Robbins, A., Sato, Y., 1988. Afferent fibers supplying the uterus in the rat. J. Neurophysiol. 59, 142-163.

Berkley, K.J., Robbins, A., Sato, Y., 1993. Functional differences between afferent fibers in the hypogastric and pelvic nerves innervating female reproductive organs in the rat. J. Neurophysiol. 69, 533-544.

Bielsky, I.F., Young, L.J., 2004. Oxytocin, vasopressin, and social recognition in mammals. Peptides 25, 1565-1574.

Bridges, R.S., 1994. The role of lactogenic hormones in maternal behavior in female rats. Acta Paediatr. Suppl. 397, 33-39.

Broad, K.D., Hinton, M.R., Keverne, E.B., Kendrick, K.M., 2002. Involvement of the medial prefrontal cortex in mediating behavioural responses to odour cues rather than olfactory recognition memory. Neuroscience $114,715-729$.
Carmichael, M.S., Humbert, R., Dixen, J., Palmisano, G., Greenleaf, W., Davidson, J.M., 1987. Plasma oxytocin increases in the human sexual response. J. Clin. Endocrinol. Metab. 64, 27-31.

Carter, C.S., 1998. Neuroendocrine perspectives on social attachment and love. Psychoneuroendocrinology 23, 779-818.

Carter, C.S., DeVries, A.C., Getz, L.L., 1995. Physiological substrates of mammalian monogamy: the prairie vole model. Neurosci. Biobehav. Rev. 19, 303-314.

Cavanaugh, B.L., Lonstein, J.S., 2010. Social novelty increases tyrosine hydroxylase immunoreactivity in the extended olfactory amygdala of female prairie voles. Physiol. Behav. 100, 381-386.

Champagne, F., Diorio, J., Sharma, S., Meaney, M.J., 2001. Naturally occurring variations in maternal behavior in the rat are associated with differences in estrogen-inducible central oxytocin receptors. Proc. Natl. Acad. Sci. U S A 98 , 12736-12741.

Champagne, F.A., Chretien, P., Stevenson, C.W., Zhang, T.Y., Gratton, A., Meaney, M.J. 2004. Variations in nucleus accumbens dopamine associated with individual differences in maternal behavior in the rat. J. Neurosci. 24, 4113-4123.

Champagne, F.A., Meaney, M.J., 2006. Stress during gestation alters postpartum maternal care and the development of the offspring in a rodent model. Biol. Psychiatry 59, 1227-1235.

Choleris, E., Little, S.R., Mong, J.A., Puram, S.V., Langer, R., Pfaff, D.W., 2007. Microparticle-based delivery of oxytocin receptor antisense DNA in the medial amygdala blocks social recognition in female mice. Proc. Natl. Acad. Sci. U S A 104, 4670-4675.

Cibrian-Llanderal, T., Rosas-Aguilar, V., Triana-Del Rio, R., Perez, C.A., Manzo, J., Garcia, L.I., Coria-Avila, G.A., 2012. Enhaced D2-type receptor activity facilitates the development of conditioned same-sex partner preference in male rats. Pharmacol. Biochem. Behav. 102, 177-183.

Coolen, L.M., Fitzgerald, M.E., Yu, L., Lehman, M.N., 2004. Activation of mu opioid receptors in the medial preoptic area following copulation in male rats. Neuroscience $124,11-21$.

Coria-Avila GA, (Ph.D.)2007. Behavioral and neural mechanisms of conditioned partner preference in the female rat. In: Psychology. Concordia University, Montreal QC, pp. 258

Coria-Avila, G.A., 2012. The role of conditioning on heterosexual and homosexual partner preferences in rats. Socioaffect. Neurosci. Psychol.

Coria-Avila, G.A., Jones, S.L., Solomon, C.E., Gavrila, A.M., Jordan, G.J., Pfaus, J.G., 2006 Conditioned partner preference in female rats for strain of male. Physiol. Behav. 88, 529-537.

Coria-Avila, G.A., Ouimet, A.J., Pacheco, P., Manzo, J., Pfaus, J.G., 2005. Olfactory conditioned partner preference in the female rat. Behav. Neurosci. 119 716-725.

Corona, R., Camacho, F.J., Garcia-Horsman, P., Guerrero, A., Ogando, A., Paredes, R.G. 2011. Different doses of estradiol benzoate induce conditioned place preference after paced mating. Horm. Behav. 60, 264-268.

Davenport Jr., R.K., Menzel Jr., E.W., Rogers, C.M., 1961. Maternal care during infancy: its effect on weight gain and mortality in the chimpanzee. Am. J. Orthopsychiatry 31, 803-809.

Davidson, J.M., Rodgers, C.H., Smith, E.R., Bloch, G.J., 1968. Stimulation of female sex behavior in adrenalectomized rats with estrogen alone. Endocrinology 82 , 193-195.

De Vries, G.J., Buijs, R.M., 1983. The origin of the vasopressinergic and oxytocinergic innervation of the rat brain with special reference to the lateral septum. Brain Res. 273, 307-317.

Devinsky, O., Morrell, M.J., Vogt, B.A., 1995. Contributions of anterior cingulate cortex to behaviour. Brain 118 (Pt 1), 279-306.

DeVries, A.C., DeVries, M.B., Taymans, S.E., Carter, C.S., 1996. The effects of stress on social preferences are sexually dimorphic in prairie voles. Proc. Natl. Acad. Sci. U S A 93, 11980-11984

Dhungel, S., Masaoka, M., Rai, D., Kondo, Y., Sakuma, Y., 2011. Both olfactory epithelial and vomeronasal inputs are essential for activation of the medial amygdala and preoptic neurons of male rats. Neuroscience 199, 225-234.

DiBenedictis, B.T., Ingraham, K.L., Baum, M.J., Cherry, J.A., 2012. Disruption of urinary odor preference and lordosis behavior in female mice given lesions of the media amygdala. Physiol. Behav. 105, 554-559.

Dienske, H., Van Vreeswijk, W., 1987. Regulation of nursing in chimpanzees. Dev. Psychobiol. 20, 71-83.

Dumais, K.M., Bredewold, R., Mayer, T.E., Veenema, A.H., 2013. Sex differences in oxytocin receptor binding in forebrain regions: correlations with social interest in brain region- and sex-specific ways. Horm. Behav. 64, 693-701.

Eichelman, B., 1983. The limbic system and aggression in humans. Neurosci. Biobehav. Rev. 7, 391-394.

Ferguson, J.N., Aldag, J.M., Insel, T.R., Young, L.J., 2001. Oxytocin in the medial amygdala is essential for social recognition in the mouse. J. Neurosci. 21, $8278-8285$.

Fleming, A.S., Korsmit, M., 1996. Plasticity in the maternal circuit: effects of materna experience on Fos-Lir in hypothalamic, limbic, and cortical structures in the postpartum rat. Behav. Neurosci. 110, 567-582.

Fleming, A.S., Rosenblatt, J.S., 1974a. Maternal behavior in the virgin and lactating rat. J. Comp. Physiol. Psychol. 86, 957-972.

Fleming, A.S., Rosenblatt, J.S., 1974b. Olfactory regulation of maternal behavior in rats. I. Effects of olfactory bulb removal in experienced and inexperienced lactating and cycling females. J. Comp. Physiol. Psychol. 86, 221-232.

Fleming, A.S., Rosenblatt, J.S., 1974c. Olfactory regulation of maternal behavior in rats. II. Effects of peripherally induced anosmia and lesions of the lateral olfactory tract in pup-induced virgins. J. Comp. Physiol. Psychol. 86, 233-246. 
Fleming, A.S., Walsh, C., 1994. Neuropsychology of maternal behavior in the rat: c-fos expression during mother-litter interactions. Psychoneuroendocrinology 19, 429-443.

Fuchs, A.R., Fuchs, F., Husslein, P., Soloff, M.S., Fernstrom, M.J., 1982. Oxytocin receptors and human parturition: a dual role for oxytocin in the initiation of labor. Science 215, 1396-1398.

Gaffori, O., Le Moal, M., 1979. Disruption of maternal behavior and appearance of cannibalism after ventral mesencephalic tegmentum lesions. Physiol. Behav. 23, 317-323.

Gandelman, R., McDermott, N.J., Kleinman, M., DeJianne, D., 1979. Maternal nest building by pseudopregnant mice. J. Reprod. Fertil. 56, 697-699.

Getz, L.L., McGuire, B., Pizzuto, T., Hofmann, J., Frase, B., 1993. Social organizat ion of the prairie vole, Microtus ochrogaster. J. Mammal. 74.

Gimpl, G., Fahrenholz, F., 2001. The oxytocin receptor system: structure, function, and regulation. Physiol. Rev. 81, 629-683.

Gingrich, B., Liu, Y., Cascio, C., Wang, Z., Insel, T.R., 2000. Dopamine D2 receptors in the nucleus accumbens are important for social attachment in female prairie voles (Microtus ochrogaster). Behav. Neurosci. 114, 173-183.

Grota, L.J., 1973. Effects of litter size, age of young, and parity on foster mother behaviour in Rattus norvegicus. Anim. Behav. 21, 78-82.

Hansen, S., Bergvall, A.H., Nyiredi, S., 1993. Interaction with pups enhances dopamine release in the ventral striatum of maternal rats: a microdialysis study. Pharmacol. Biochem. Behav. 45, 673-676.

Hawtin, S.R., Wesley, V.J., Parslow, R.A., Patel, S., Wheatley, M., 2000. Critical role of a subdomain of the $\mathrm{N}$-terminus of the $\mathrm{V} 1$ a vasopressin receptor for binding agonists but not antagonists; functional rescue by the oxytocin receptor $\mathrm{N}$-terminus. Biochemistry 39, 13524-13533.

Heimer, L., Zahm, D.S., Churchill, L., Kalivas, P.W., Wohltmann, C., 1991. Specificity in the projection patterns of accumbal core and shell in the rat. Neuroscience 41, 89-125.

Hoeger, K.M., Kolp, L.A., Strobl, F.J., Veldhuis, J.D., 1999. Evaluation of LH secretory dynamics during the rat proestrous LH surge. Am. J. Physiol. 276, R219-R225.

Inoue, S., Kamiyama, H., Matsumoto, M., Yanagawa, Y., Hiraide, S., Saito, Y., Shimamura, K., Togashi, H., 2013. Synaptic modulation via basolateral amygdala on the rat hippocampus-medial prefrontal cortex pathway in fear extinction. J. Pharmacol. Sci. 123, 267-278.

Insel, T.R., 1992. Oxytocin - a neuropeptide for affiliation: evidence from behavioral, receptor autoradiographic, and comparative studies. Psychoneuroendocrinology $17,3-35$.

Insel, T.R., 2003. Is social attachment an addictive disorder? Physiol. Behav. 79, 351-357.

Insel, T.R., Gingrich, B.S., Young, L.J., 2001. Oxytocin: who needs it? Prog. Brain Res. 133, 59-66.

Insel, T.R., Shapiro, L.E., 1992. Oxytocin receptor distribution reflects social organization in monogamous and polygamous voles. Proc. Natl. Acad. Sci. U S A 89 5981-5985.

Insel, T.R., Young, L.J., 2001. The neurobiology of attachment. Nat. Rev. Neurosci. 2, $129-136$.

Ipser, J.C., Terburg, D., Syal, S., Phillips, N., Solms, M., Panksepp, J., Malcolm-Smith, S., Thomas, K., Stein, D.J., van Honk, J., 2013. Reduced fear-recognition sensitivity following acute buprenorphine administration in healthy volunteers Psychoneuroendocrinology 38, 166-170.

Jakubowski, M., Terkel, J., 1985. Transition from pup killing to parental behavior in male and virgin female albino rats. Physiol. Behav. 34, 683-686.

Johns, J.M., Noonan, L.R., Zimmerman, L.I., Li, L., Pedersen, C.A., 1994. Effects of chronic and acute cocaine treatment on the onset of maternal behavior and aggression in Sprague-Dawley rats. Behav. Neurosci. 108, 107-112.

Kalivas, P.W., Abhold, R., 1987. Enkephalin release into the ventral tegmental area in response to stress: modulation of mesocorticolimbic dopamine. Brain Res. 414, 339-348.

Keer, S.E., Stern, J.M., 1999. Dopamine receptor blockade in the nucleus accumbens inhibits maternal retrieval and licking, but enhances nursing behavior in lactating rats. Physiol. Behav. 67, 659-669.

Keller, M., Perrin, G., Meurisse, M., Ferreira, G., Levy, F., 2004. Cortical and medial amygdala are both involved in the formation of olfactory offspring memory in sheep. Eur. J. Neurosci. 20, 3433-3441.

Kelliher, K.R., Liu, Y.C., Baum, M.J., Sachs, B.D., 1999. Neuronal Fos activation in olfactory bulb and forebrain of male rats having erections in the presence of inaccessible estrous females. Neuroscience 92, 1025-1033.

Kendrick, K.M., Da Costa, A.P., Broad, K.D., Ohkura, S., Guevara, R., Levy, F., Keverne, E.B., 1997. Neural control of maternal behaviour and olfactory recognition of offspring. Brain Res. Bull. 44, 383-395.

Kendrick, K.M., Hinton, M.R., Atkins, K., Haupt, M.A., Skinner, J.D., 1998. Mothers determine sexual preferences. Nature 395, 229-230.

Kendrick, K.M., Levy, F., Keverne, E.B., 1991. Importance of vaginocervical stimulation for the formation of maternal bonding in primiparous and multiparous parturient ewes. Physiol. Behav. 50, 595-600.

Keverne, E.B., Levy, F., Poindron, P., Lindsay, D.R., 1983. Vaginal stimulation: an important determinant of maternal bonding in sheep. Science $219,81-83$.

Kippin, T.E., Cain, S.W., Pfaus, J.G., 2003. Estrous odors and sexually conditioned neutral odors activate separate neural pathways in the male rat. Neuroscience 117, 971-979.

Kippin, T.E., Pfaus, J.G., 2001. The development of olfactory conditioned ejaculatory preferences in the male rat. I. Nature of the unconditioned stimulus. Physiol. Behav. 73, 457-469.
Kippin, T.E., Samaha, A.N., Sotiropoulos, V., Pfaus, J.G., 2001. The development of olfactory conditioned ejaculatory preferences in the male rat. II. Parametric manipulation of conditioning session number and duration. Physiol. Behav. 73 471-485.

Kippin, T.E., Talinakis, E., Chattmann, L., Bartholomew, S., Pfaus, J.G., 1998. Olfactory conditioning of sexual behavior in the male rat (Rattus norvegicus). J Comp Psychol, 112.

Klitenick, M.A., Deutch, A.Y., Churchill, L., Kalivas, P.W., 1992. Topography and functional role of dopaminergic projections from the ventral mesencephalic tegmentum to the ventral pallidum. Neuroscience 50, 371-386.

Komisaruk, B.R., Rosenblatt, J.S., Barona, M.L., Chinapen, S., Nissanov, J., O’Bannon, R.T., Johnson, B.M., Del Cerro, M.C., 2000. Combined c-fos and 14C-2deoxyglucose method to differentiate site-specific excitation from disinhibition: analysis of maternal behavior in the rat. Brain Res. 859, 262-272.

Lahoud, N., Maroun, M., 2013. Oxytocinergic manipulations in corticolimbic circuit differentially affect fear acquisition and extinction. Psychoneuroendocrinology 38, 2184-2195.

Lee, A., Clancy, S., Fleming, A.S., 2000. Mother rats bar-press for pups: effects of lesions of the mpoa and limbic sites on maternal behavior and operant responding for pup-reinforcement. Behav. Brain Res. 108, 215-231.

Lee, A., Li, M., Watchus, J., Fleming, A.S., 1999. Neuroanatomical basis of maternal memory in postpartum rats: selective role for the nucleus accumbens. Behav. Neurosci. 113, 523-538.

Lee, J.W., Erskine, M.S., 1996. Vaginocervical stimulation suppresses the expression of c-fos induced by mating in thoracic, lumbar and sacral segments of the female rat. Neuroscience 74, 237-249.

Lim, M.M., Young, L.J., 2004. Vasopressin-dependent neural circuits underlying pai bond formation in the monogamous prairie vole. Neuroscience $125,35-45$.

Lisk, R.D., Barfield, M.A., 1975. Progesterone facilitation of sexual receptivity in rats with neural implantation of estrogen. Neuroendocrinology 19, 28-35.

Liu, Y., Wang, Z.X., 2003. Nucleus accumbens oxytocin and dopamine interact to regulate pair bond formation in female prairie voles. Neuroscience 121, 537-544.

Lonstein, J.S., Simmons, D.A., Swann, J.M., Stern, J.M., 1998. Forebrain expression of c-fos due to active maternal behaviour in lactating rats. Neuroscience 82 , 267-281.

Marson, L., Murphy, A.Z., 2006. Identification of neural circuits involved in female genital responses in the rat: a dual virus and anterograde tracing study. Am. J. Physiol. Regul. Integr. Comp. Physiol. 291, R419-R428.

Menetrey, D., Basbaum, A.I., 1987. Spinal and trigeminal projections to the nucleus of the solitary tract: a possible substrate for somatovisceral and viscerovisceral reflex activation. J. Comp. Neurol. 255, 439-450.

Mennella, J.A., Moltz, H., 1988. Infanticide in rats: male strategy and female counterstrategy. Physiol. Behav. 42, 19-28.

Misner, T.L., Houpt, K.A., 1998. Animal behavior case of the month. Aggression that began 4 days after ovariohysterectomy. J. Am. Vet. Med. Assoc. 213, $1260-1262$.

Mouton, L.J., VanderHorst, V.G., Holstege, G., 1997. Large segmental differences in the spinal projections to the periaqueductal gray in the cat. Neurosci. Lett. 238, $1-4$.

Nelson, R.J., 2000. An Introduction to Behavioral Endocrinology. Sinauer Associates, Sunderland, Massachusetts.

Neumann, I., Russell, J.A., Landgraf, R., 1992. Endogenous opioids regulate intracerebral oxytocin release during parturition in a region-specific manner. Prog. Brain Res. 91, 55-58.

Numan, M., Numan, M.J., Pliakou, N., Stolzenberg, D.S., Mullins, O.J., Murphy, J.M., Smith, C.D., 2005. The effects of D1 or D2 dopamine receptor antagonism in the medial preoptic area, ventral pallidum, or nucleus accumbens on the maternal retrieval response and other aspects of maternal behavior in rats. Behav. Neurosci. 119, 1588-1604.

Parada, M. Abdul-Ahad, F., Censi, S., Sparks, L., Pfaus, J.G., 2011. Context alters the ability of clitoral stimulation to induce a sexually-conditioned partner preference in the rat. Horm. Behav..

Parada, M., Chamas, L., Censi, S., Coria-Avila, G., Pfaus, J.G., 2010. Clitoral stimulation induces conditioned place preference and Fos activation in the rat. Horm. Behav. 57, 112-118.

Paredes-Ramos, P., Miquel, M., Manzo, J., Coria-Avila, G.A., 2011. Juvenile play conditions sexual partner preference in adult female rats. Physiol. Behav. 104, 1016-1023.

Paredes-Ramos, P., Miquel, M., Manzo, J., Pfaus, J.G., Lopez-Meraz, M.L., Coria-Avila, G.A., 2012. Tickling in juvenile but not adult female rats conditions sexual partner preference. Physiol. Behav. 107, 17-25.

Parkinson, J.A., Cardinal, R.N., Everitt, B.J., 2000. Limbic cortical-ventral striatal systems underlying appetitive conditioning. Prog. Brain Res. 126, 263-285.

Pfaus, J.G., 2009. Pathways of sexual desire. J. Sex Med. 6, 1506-1533.

Pfaus, J.G., Damsma, G., Nomikos, G.G., Wenkstern, D.G., Blaha, C.D., Phillips, A.G., Fibiger, H.C., 1990. Sexual behavior enhances central dopamine transmission in the male rat. Brain Res. 530, 345-348.

Pfaus, J.G., Damsma, G., Wenkstern, D., Fibiger, H.C., 1995. Sexual activity increases dopamine transmission in the nucleus accumbens and striatum of female rats. Brain Res. 693, 21-30.

Pfaus, J.G., Kippin, T.E., Centeno, S., 2001. Conditioning and sexual behavior: a review. Horm. Behav. 40, 291-321.

Pfaus, J.G., Kippin, T.E., Coria-Avila, G.A., Gelez, H., Afonso, V.M., Ismail, N., Parada, M., 2012. Who, what, where, when (and maybe even why)? How the experience of sexual reward connects sexual desire, preference, and performance. Arch. Sex. Behav. 41, 31-62. 
G Model

NBR 1938 1-10

10

G.A. Coria-Avila et al. / Neuroscience and Biobehavioral Reviews $x x x$ (2014) $x x x-x x x$

1040

1041

1042

1043

1044

1045

1047

1048

1049

1050

1052

1053

1054

1055

1056

1057
1058

1058
1059

1060

1061

1062

1063

1064

1065
1066

1066

1068
Phillips-Farfan, B.V., Fernandez-Guasti, A., 2009. Endocrine, neural and pharmacological aspects of sexual satiety in male rats. Neurosci. Biobehav. Rev. 33 , 442-455.

Rodriguez-Manzo, G., Fernandez-Guasti, A., 1995. Opioid antagonists and the sexual satiation phenomenon. Psychopharmacology (Berl) 122, 131-136.

Rosenblatt, J.S., 1967. Nonhormonal basis of maternal behavior in the rat. Science 156, 1512-1514.

Rosenblatt, J.S., Hazelwood, S., Poole, J., 1996. Maternal behavior in male rats: effects of medial preoptic area lesions and presence of maternal aggression. Horm. Behav. 30, 201-215.

Rosenblatt, J.S., Mayer, A.D., Giordano, A.L., 1988. Hormonal basis during pregnancy for the onset of maternal behavior in the rat. Psychoneuroendocrinology 13, 29-46.

Schally, A.V., Arimura, A., Kastin, A.J., Matsuo, H., Baba, Y., Redding, T.W., Nair, R.M., Debeljuk, L., White, W.F., 1971. Gonadotropin-releasing hormone: one polypeptide regulates secretion of luteinizing and follicle-stimulating hormones. Science $173,1036-1038$.

Schulte, I., Hoy, S., 1997. Nursing and suckling behavior and mother-child contacts in domestic rabbits. Berl. Munch. Tierarztl. Wochenschr. 110, 134-138.

Shahrokh, D.K., Zhang, T.Y., Diorio, J., Gratton, A., Meaney, M.J., 2010. Oxytocin-dopamine interactions mediate variations in maternal behavior in the rat. Endocrinology 151, 2276-2286.

Sofroniew, M.V., Weindl, A., Schrell, U., Wetzstein, R., 1981. Immunohistochemistry of vasopressin, oxytocin and neurophysin in the hypothalamus and extrahypothalamic regions of the human and primate brain. Acta Histochem. Suppl. 24, 79-95.

Stack, E.C., Balakrishnan, R., Numan, M.J., Numan, M., 2002. A functional neuroanatomical investigation of the role of the medial preoptic area in neural circuits regulating maternal behavior. Behav. Brain Res. 131, 17-36.
Steuer, M.A., Thompson, A.C., Doerr, J.C., Youakim, M., Kristal, M.B., 1987. Induction of maternal behavior in rats: effects of pseudopregnancy termination and placenta-smeared pups. Behav. Neurosci. 101, 219-227.

Szechtman, H., Lambrou, P.J., Caggiula, A.R., Redgate, E.S., 1974. Plasma corticosterone levels during sexual behavior in male rats. Horm. Behav. 5, 191-200.

Terkel, J., Rosenblatt, J.S., 1972. Humoral factors underlying maternal behavior at parturition: corss transfusion between freely moving rats. J. Comp. Physiol. Psychol. 80, 365-371.

Ueyama, T., Arakawa, H., Mizuno, N., 1987. Central distribution of efferent and afferent components of the pudendal nerve in rat. Anat. Embryol. (Berl) 177, 37-49.

vom Saal, F.S., 1985. Time-contingent change in infanticide and parental behavior induced by ejaculation in male mice. Physiol. Behav. 34, 7-15.

von Keyserlingk, M.A., Weary, D.M., 2007. Maternal behavior in cattle. Horm. Behav. $52,106-113$.

Walsh, C.J., Fleming, A.S., Lee, A., Magnusson, J.E., 1996. The effects of olfactory and somatosensory desensitization on Fos-like immunoreactivity in the brains of pup-exposed postpartum rats. Behav. Neurosci. 110, 134-153.

Wardlaw, S.L., Frantz, A.G., 1983. Brain beta-endorphin during pregnancy, parturition, and the postpartum period. Endocrinology 113, 1664-1668.

Williams, J.R., Catania, K.C., Carter, C.S., 1992. Development of partner preferences in female prairie voles (Microtus ochrogaster): the role of social and sexual experience. Horm. Behav. 26, 339-349.

Young, L.J., Lim, M.M., Gingrich, B., Insel, T.R., 2001. Cellular mechanisms of social attachment. Horm. Behav. 40, 133-138.

Young, L.J., Murphy Young, A.Z., Hammock, E.A., 2005. Anatomy and neurochemistry of the pair bond. J. Comp. Neurol. 493, 51-57.

Young, L.J., Wang, Z., 2004. The neurobiology of pair bonding. Nat. Neurosci. 7, 1048-1054.

Yucel, S., Baskin, L.S., 2004. An anatomical description of the male and female urethral sphincter complex. J. Urol. 171, 1890-1897.
1069

1070

1071

1073

1074

1075

1076

1077

1079

1080

1081

1082

1083

1084

1085

1086
1087

1088

1089

1090

1092

1093

1094

1095

1096
1097

1098

Please cite this article in press as: Coria-Avila, G.A., et al., Neurobiology of social attachments. Neurosci. Biobehav. Rev. (2014), http://dx.doi.org/10.1016/j.neubiorev.2014.04.004 